International Journal of Social Sciences and Humanities
Available online at http://sciencescholar.us/journal/index.php/ijssh
Vol. 2 No.3, December 2018, pages: $196 \sim 204$
e-ISSN: 2550-7001, p-ISSN: 2550-701X
https://doi.org/10.29332/ijssh.v2n3.238

\title{
International Communication of Intangible Cultural Heritage in Central Plains: A Case Study of Chinese Wushu
}

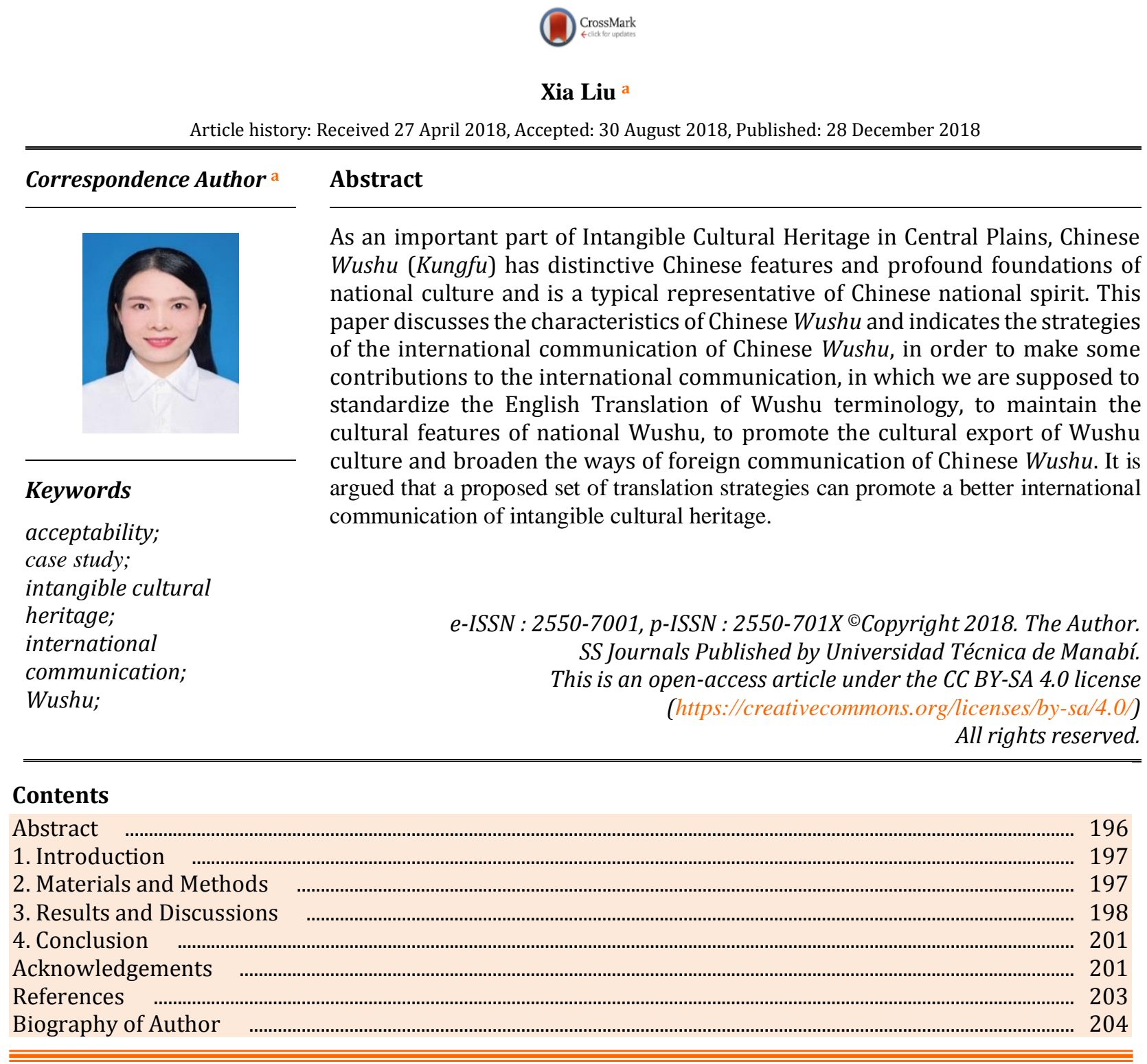

a Faculty of International Studies, Henan Normal University, China 


\section{Introduction}

According to the UNESCO Convention for the Safeguarding of the Intangible Cultural Heritage (2003), intangible cultural heritage refers to a variety of traditional cultural expressions that exist in a non-physical form, are closely related to the lives of the people and inherited from generation to generation, including oral traditions and forms of expression, performing arts, social practices, ceremonies and festivals, knowledge and practice of nature and the universe, as well as traditional handicrafts and cultural spaces associated with these traditional cultural expressions. Intangible cultural heritage is passed down by human beings orally or by action. It is known as the "living fossil" of history and culture and the "back of national memory". It shares the civilization of human societies with the material cultural heritage and is the embodiment of the world's cultural diversity.

China is the country with the largest number of representative works of the United Nations intangible cultural heritage. However, with the acceleration of the world economic and cultural integration, China's cultural ecology has undergone tremendous changes, and the intangible cultural heritage has been increasingly impacted. Culture faces the challenge of living in a modern gap. How to protect the cultural heritage of the nation and inherit and carry forward the cultural heritage of the nation is related to the survival of a nation when the local culture faces the strong impact and collision of strong culture and foreign culture. Strengthening the protection of China's intangible cultural heritage becomes an urgent task.

The protection of intangible cultural heritage is also guaranteed in many forms. The Opinions on Strengthening the Protection of Intangible Cultural Heritage in China (2005), stated clearly that the goal of China's protection of intangible cultural heritage is: "Through the efforts of the whole society, a relatively complete intangible cultural heritage protection system with Chinese characteristics has been gradually established to protect China's precious and endangered intangible cultural heritage with historical, cultural and scientific value, and to inherit and carry it forward". The Intangible Cultural Heritage Law officially promulgated by China in 2011 regulates the protection of intangible culture in the form of legislation. It can be seen that communication is the purpose of the protection of intangible cultural heritage.

Based on the current situation described above, this research tends to analyze the essence of the intangible cultural heritage of the central plains, mainly focusing on the martial arts culture.

\section{Materials and Methods}

This section mainly reports the analyzed materials selected, general approaches as well as the analysis process.

First, as for the materials to be analyzed, this research selects two major sources. One is the English translation of the introduction of martial arts from major websites such as Shaolin Temple. The other source is the selected printed texts from the representative works, such as Yang (2006), as well as other important books and magazines.

As for the analysis approach and process, the current research adopts a content analysis approach (Krippendorff, 2012). To be specific, the selected materials are first transcribed into clean texts. Through reading through the translated texts, the researcher identifies the emerging themes in terms of the typical terminology translations. Following a bottom-up approach, the current research collected some key patterns of translation features. The major findings are to be reported with detailed examples in the next section. It has been demonstrated that an inductive approach is suitable for the analysis of text features (Patton, 2002). In this way, the major features emerge naturally and the findings are trustworthy.

Besides the analyzed materials and methods mentioned above, some distinctive background information needs to be introduced. The region of Central Plains is one of the birthplaces of ancient Chinese civilization and the cradle of the Chinese nation. Since ancient times, human beings have prospered here and created a splendid Central Plains culture. Among them is the tangible cultural heritage in the form of material, and the intangible cultural heritage mainly passed down through oral communication. It covers almost all the UNESCO-published Convention on the Safeguarding of the Intangible Cultural Heritage. It includes traditional performing arts, folk activities, festival etiquette, traditional handicraft skills, and oral traditions, with various forms, rich contents,

Liu, X. (2018). International communication of intangible cultural heritage in central plains: a case study of Chinese Wushu. International Journal of Social Sciences and Humanities, 2(3), 196-204. https://doi.org/10.29332/ijssh.v2n3.238 
a long history and strong regional and original features. The most original intangible cultural heritage in the Central Plains is martial arts. Chinese martial arts are also called Chinese Kung Fu. It is called "martial arts" in mainland China and is called "Kung Fu" overseas. It is a kind of ability for both sides to defeat the other. But martial art is not only a fighting skill, but it also integrates with other Chinese cultural forms such as philosophy, religion, military science, medicine and art to form traditional items with unique national style, which is the essence of Chinese civilization.

\section{Results and Discussions}

This section mainly discusses the existing translating practices and proposes a set of translation strategies for the sake of international communication of central plains martial arts culture. It should be noted that the purpose of this section is not to offer practical translating techniques but to put forward four general guiding principles. Based on the analysis of the selected materials mentioned in the previous section, general findings of the translation features will be presented first.

Generally, Kungfu of Shaolin Temple is a wonderful work of Chinese martial arts culture. The deep integration of Zen and $W u$ in Shaolin Kungfu, the formation of meditation as internal strength, highlighting the wisdom of martial arts training to understand the meditation, Zen and Wu so that Shaolin Kungfu shows a unique style. After the formation of Shaolin Kungfu, it was circulated among the people, and the formation of many martial arts schools and boxing are influenced by it. Shaolin Kungfu is not only widely spread in China, but also has a great influence abroad. Japan and Southeast Asia are the places where Shaolin Kungfu is well-accepted. Every year, a good number of international visitors from all over the world go to the Central Plains of China to study Shaolin Kungfu and set off a wave of learning Chinese martial arts around the world.

Chinese Taijiquan also represents the essence of Chinese martial arts. It is not only a traditional boxing technique that combines self-cultivation and fitness but also has both internal and external training. It has won the essence of Chinese traditional "Easy" culture and "Dao" culture, and it embodies the rich Chinese classical philosophy. As early as July 2000, the International Wushu Federation decided to set the annual may as "world taijiquan month". According to statistics, fans from more than 60 countries around the world have come to China to study Taijiquan, and the number of people practicing Tai Chi has reached 150 million. In 2005, taijiquan was introduced to more than 100 countries and regions. More than 70 countries and regions around the world have established taijiquan organizations, and taijiquan has become the world's first martial art.

As the accumulation of Chinese traditional culture, the martial arts culture has continuously absorbed many traditional cultural ideas and concepts such as traditional philosophy, ethics, health science, military law, Chinese medicine, aesthetics, etc., martial arts culture and traditional Chinese culture. Martial arts culture and traditional Chinese culture in the same line, the integration of Chinese culture is an important carrier and perfect embodiment. The external communication of martial arts culture can not only show the wisdom of the Chinese people, spread the traditional culture of the Chinese nation, improve the status of the Chinese nation in the world's national forests, but also promote the development of world civilization, and then achieve the goal of improving China's cultural soft power.

Based on the preliminary discussion, the research proposes four general guiding principles for the sake of international communication of central plains martial arts culture.

\subsection{Standardize the English expressions of martial art terminology and promote the external communication of martial arts culture}

The martial art terminology is a set of terms on professional, cultural and national levels. It is the most basic expression and communication language of martial arts professional technology and theoretical knowledge. Therefore, the standardization of martial arts terminology plays a crucial role in the external communication of martial arts culture.

First of all, in terms of "martial art", "Common vocabulary for English and Chinese sports"(1980), "Common vocabulary of English-Chinese and English martial arts"(1989), "Encyclopedia of sports" (1998) and "EnglishChinese Chinese-English Olympic Dictionary" (2003) both use "martial art" to refer to Wushu. But in the Collins COBUILD English Language Dictionary, "martial art" is interpreted as "(eastern) martial arts (such as kung fu, 
karate, judo, etc.)". In the Webster's Sports Dictionary, martial art is defined as "a variety of skills that are widely practiced as a sport in the East, including karate, judo, time, jujitsu, sumo and taekwondo" (Du, 2010). In addition, the term "martial art" is often seen on other occasions. For example, the English name of the film Shaolin Temple, which made Jet Li famous in 1982, is Martial Arts of Shaolin. Furthermore, SMA (Standing Martial Arts), the main project of the international martial arts fighting competition, is an excellent sport that combines entertainment and competition. It is the perfect combination of boxing, taekwondo, karate, and Muay Thai and it is the decathlon of the fighting sport.

The Modern Chinese Dictionary points out that martial art, also known as national art or martial arts, is a traditional Chinese sport that takes hammer as the main content and focuses on both inside and outside in the form of routines and captures. Today's martial arts mainly include social philosophy, Chinese medicine, ethics, military science, aesthetics, qigong, and many other traditional cultural ideas and cultural concepts, focusing on internal and external meditation, such as the theory of holism, Yin-yang change, form and spirit, Qi, static and movement, rigid and soft, and so on, rich in connotation and profound in implication, it not only has the common characteristics of strengthening the body and body in human sports, but also has the special philosophical, scientific and artistic characteristics of Oriental civilization, which reflects the Chinese people's wisdom crystallization in the field of sports more intensively. Therefore, in a broad sense, martial art is not only a sports project but also a national sport. It is a valuable cultural heritage accumulated by the Chinese people for a long time (Zhang, 2003).

From the above analysis, it can be found that "martial art" pays attention to fighting and confrontation, fitness and self-defense, as well as skills of hitting, while Chinese martial arts include the characteristics of Tai Chi, the Five Elements, the Eight Diagrams, the yin and yang, the traditional Chinese medicine meridians, the qi, the combination of heaven and man, and the self-cultivation of Confucianism cannot be reflected in the word "martial art". As early as 1963, in Bruce Lee's "Chinese Kung-fu", Westerners had already remembered the term "Kungfu". We don't have to worry about the acceptance of Westerners. Now, we usually use the spelling method "Kungfu". Therefore, "Wushu" and "Kungfu" can more accurately and completely reflect the cultural connotation and essence of Chinese martial arts.

Secondly, with regard to "Tai Chi", the term has traditionally been translated as "shadow boxing". In the Websters Sports Dictionary, "shadow boxing" refers to "practicing moving and hitting by punching with an imaginary enemy", while in Collins Cobuild English Language Dictionary, the interpretation of "Tai Chi" is "Air combat and defense exercises". It can be seen that shadow boxing is similar in shape but not in spirit. It does not reflect the characteristics of Tai Chi Quan's self-cultivation and nourishment. The concept of "Taijiquan" cannot be integrated into the concept of "Taijiquan". It is also impossible to integrate the cosmology of "people those who practice Tai chi should be integrated Yin and Yang into an entirety in their heart". Therefore, using "Taijiquan" is more appropriate.

At present, the word "martial art" has been translated as "wushu" by the International Wushu Federation. This is the need of the times and is also convenient for international communication. In addition, "Qigong", "Bagua", "Shaolin", "Changquan" and so on, these have been widely accepted by the English native language group, which is more conducive to the spread of Chinese martial arts.

Qiu (2001), put forward the concept of "zero translation" in the article "Translatability and Zero Translation", that is, the so-called zero translation is a ready-to-use word in the language that is used to translate the words in the source language. Here, there are two meanings: 1) Words in the source text are not translated deliberately; (2) Words that are not translated into the source text of the ready-made words in the target language. On the basis of fully considering cultural differences, the concept of "zero translation" appearing in the context of intercultural communication is a martial arts term, especially providing powerful theoretical support for the translation of a large number of cultural vacancies in martial arts texts. However, it should be used scientifically to avoid the phenomenon of inadequate translation.

\subsection{Maintain the cultural characteristics of national martial arts and carry forward the national spirit of martial arts culture}

The culture of a nation often embodies the historical cognition and realistic feel of the nation towards the world and life. It also often accumulates the deepest spiritual pursuit and code of conduct of this nation (Wang, 2005: 39). Culture is the premise and condition for a nation to survive. If a nation gets rid of its own cultural

Liu, X. (2018). International communication of intangible cultural heritage in central plains: a case study of Chinese Wushu. International Journal of Social Sciences and Humanities, 2(3), 196-204. 
characteristics, it loses its soul as well as its existence value. Martial art grows mature in Chinese culture. It is not only a part of Chinese culture but also contains all kinds of outstanding elements of Chinese culture. It is a wonderful epitome of Chinese culture. Shaolin Kungfu takes Buddhism as its background. Wuzhong contains Zen, self-cultivation, uniqueness, and profoundness. Taijiquan, both internal and external, with softness, soothing and strong, won the essence of Chinese traditional " $Y i$ " culture and "Dao" culture, reflecting the rich Chinese classical philosophy. These precious gifts must be inherited, protected and carried forward by us in the external communication of Chinese culture. Because, "If we can't pass on what we inherited from our ancestors, there is not much left that we can pass on to later generations; and once globalization has eroded our ability or willingness to pass on traditional values, we will sit idle and become degraded, becoming victims of low-level pseudo-cultures that is geared toward ratings, advertising revenue, and sales metrics, and seeks mass effect" (Schmidt, 2001: 62 ).

As a high-density Chinese culture carrier, martial art has distinct characteristics compared with others. First of all, there are a lot of philosophical terms in martial arts texts. In Chinese classical philosophy, the objective laws of the growth, change, and extinction of everything in nature can be returned to Yin and Yang, and martial arts is no exception. For example, "moving is yang, static is yin; the shot is yang, closing is yin; rigid is yang, soft is yin...". These abstract conceptual philosophical concepts are used in martial arts culture to give new meaning to readers of other cultures are more difficult to accept. Secondly, one of the prominent features of ancient Chinese culture is the intuition and meaning. Its thinking characteristics are vague, speculative and empirical. It is reflected in the martial arts language that there are quite a few concepts of the signifier and the reference is not fixed. For example, "spirit" in "inner spirits, external muscles and bones" are more abstract, and different sects have different interpretations. Thirdly, the authors of some martial arts classics have a literary foundation, so they have a strong literary flavor. There are a large number of verses and poems in martial arts classics. They use rhetoric, anthropomorphism, exaggeration and other rhetorical techniques, such as "The shape is like a running rabbit, the spirit is like the mouse cat", "There is no temperament like a nine-curve bead; no matter how bad it is; the strength is like a hundred steel-making, it is invincible" (Xie, 2008: 61). These characteristics of martial arts text pose a higher challenge to the external communication of martial arts.

For example, Chinese martial arts often mention "Qi Chen Dan Tian". Dantian generally refers to "the navel (the gods), then to the sun, the life gate part (small abdomen), not just a point, not a single plane, but from the outside to the inside, from top to bottom part." The so-called "Qi Shen Dan Tian" is a relatively complicated qigong process. From the perspective of modern science, it is a "neural reflex process" (Dong, 1990), which is not simple breathing. But most of the texts use "Inhale deeply (into the abdomen)", that is, "inhale into the abdomen" to express this concept, such as "Chen Style Taijiquan Competition Routine" by Shanxi Science and Technology Press, the English version of the "Henan: Cultural Great Central Plains" so on. Such a simple understanding equates Dantian with the abdomen; equating the vomiting activity under the control of thought with simple abdominal breathing, although the surface seems easy to understand and easy to operate, it actually hurts the national cultural connotation of Chinese martial arts. It will also cause misinterpretation of other national martial arts enthusiasts. In the process of external communication, we must pay attention to the protection of national cultural characteristics. Here we should use the method of transliteration and annotation to interpret it as "Dantian (the place roughly under the omphalos)".

For another example, Shaolin martial arts pay attention to "inner training--jing, qi, shen and outside training-hands, eyes, body". Jingshen is known as the "three treasures of the human body" and is the basis for maintaining human life activities. Among them, jing and $q i$ are the basic substances that constitute the human body, and they are the basis for the physiological activities of organs. Shen is the general term for life phenomena. The three are closely related, and they can be refined, and the gas can be refined. The jing and the $q i$ can be turned into shen, so the jing is full of $q i$, and the jing is full of vitality. Through the martial arts exercise, "refining the refined gas, refining the gas, refining the gods, refining the spirit is still virtual" , thereby enhancing vitality (Yang, 2006: 32). The explanations for "jing, qi, and shen" are also inconsistent. There are generally "vigor, morale and spirit", "essence, energy and spirit" and "jing qi and shen" (Luo Yongzhou 2008). The author believes that it is more appropriate to use transliteration to explain it as "jing(body essence), $q i$ (vital energy), and shen (mentality)". This not only preserves the traditional cultural characteristics of the source language but also facilitates the understanding of the target readers and promotes cultural exchange and communication. The translator should respect the final interpretation right of the source language culture in the spirit of being highly responsible for the source language culture. Otherwise, any translation is to take the 
system out of context and to separate and dismember the source language culture, thus it is cross-cultural discourse violence (Liu, 2006).

\subsection{Promote the cultural output of Chinese martial arts and show the charm of the martial arts culture}

Chinese martial art was originated from China and belongs to the world. The competition of cultural soft power plays an important role in the global competition. In addition to being physically fit and self-cultivating, Chinese martial art, as a cultural carrier of China, is also a cultural messenger of communication with the world. It plays an active role in promoting the development of human health, world friendship and international cultural economy. It also has enhanced China's national soft power in the world, expanded the influence of Chinese culture in the world, and constantly shaped the image of China's "peaceful rise" of civilized and progressive cultural powers (Huang, 2012).

Wushu is an outstanding traditional sports project of the Chinese nation. It represents the character of the Chinese nation, is the value choice of the entire nation, has a profound mass base, and its unique fitness and health model contributes to the unique strength of the Chinese nation for the health of the world. The unique charm of the Chinese nation is also the basis for the spread of Chinese martial arts.

The nationality is also the world. The spread of martial arts is to balance the relationship between the two developments and living environment of martial arts at home and abroad. It is necessary to base on the inheritance, development, and popularization of the country, and further expand its international influence. Actively promoted overseas, so that other ethnic groups can understand the character of the Chinese nation through learning Chinese martial arts and improve China's international influence.

At present, we hold regular international festivals, such as Zhengzhou International Shaolin Wushu Festival and Jiaozuo International Taijiquan Exchange Contest. These not only shapes the charm of the "Kung Fu" brand of Chinese martial arts but also builds a good platform for Chinese martial arts to go further into the world. These international martial arts brands are the golden business cards of China and have become the bonds of friendly exchanges between Chinese people and the people of the world (Guo, 2006). At the same time, it also creates conditions for the world communication of Chinese martial arts, and promote the prosperity of Chinese culture and economic development.

Chinese martial arts are deeply rooted in the soil of Chinese traditional culture and are in line with Chinese traditional culture. When we spread martial arts to the world, we must spread Chinese traditional culture. The majority of people around the world practice Chinese martial arts in order to "understand Chinese culture (98.32\% of the martial arts population)" (Hu, 2007). After 2008, we entered the post-Olympic era. Chinese martial arts should have its own development path and base on traditional culture. "Increase the output of Chinese martial arts. First of all, because this is an important part of promoting Chinese cultural output, we should pay more attention to Pay attention to the output of "cultural martial arts" (Wang, 2009). Today, with the increasing frequency of international exchanges, we should show the charm of Chinese traditional culture to the people of the world, and strive to improve the influence of the Chinese traditional culture, so that people of all nationalities in the world have the opportunity to appreciate the essence of Chinese traditional culture-martial arts culture. The unique charm, which contributes to China's promotion of international influence.

\subsection{Broaden the martial arts' external communication channels and improve the competitive power of martial arts culture}

Since the end of the $20^{\text {th }}$ century, human beings have entered the "second media era", and the rapid development of the network has revolutionized the entire society. The advent of the Internet age has provided modern technical support for the dissemination of intangible cultural heritage, and the intangible cultural heritage has a broader space for communication. Of course, this is only an objective condition for the widespread dissemination of intangible cultural heritage. What determines the role is the people and nation, as well as people's awareness of traditional culture and the degree of emphasis. Under the grim situation of the current Western thoughts and large-scale invasion of ideas, we should strive to strengthen the national centripetal force and cohesiveness of the Chinese nation, attach importance to the traditional culture of the Chinese nation, especially the intangible cultural heritage, and enhance the people's cultural identity and national pride.

Liu, X. (2018). International communication of intangible cultural heritage in central plains: a case study of Chinese Wushu. International Journal of Social Sciences and Humanities, 2(3), 196-204. https://doi.org/10.29332/ijssh.v2n3.238 
In addition to traditional legislation, propaganda and other means, we should make full use of the advantages of the network, through the establishment of intangible cultural heritage information resources and intangible cultural heritage sites, etc., the intangible cultural heritage of the folk, traditional things really go deep into the hearts of the people, return to the society, and complete the virtuous cycle of taking it to the people, using it for the people, and serving the people. In view of the particularity of Chinese martial arts culture, we should fully consider the cultural differences in the establishment of information resources, and adopt the methods of texts, including illustrations and audiovisuals to achieve the best external communication of martial arts culture.

The external communication of martial arts culture depends not only on the promotion of official cultural exchange centers and bases but also on the functions of folk martial arts organizations. Through the establishment of martial arts, military schools, cultural centers, and other organizations, through the organization of tour performances, martial arts exchange meetings, training courses Various events such as competitions have enabled Chinese martial arts to truly go abroad and attract more attention from different parts of the world.

\section{Conclusion}

The inheritance and spread of intangible cultural heritage is an arduous and meaningful long-term project. As the process of world integration accelerates, global interaction becomes more and more obvious. Under this circumstance, the dialogue of civilizations in the international community is becoming more and more important, and the rich intangible cultural heritage of the Central Plains, which can represent the living history of the Chinese nation to a large extent, has become an inevitable requirement for the dialogue of civilizations in the international community (Shi \& Jiang, 2008). In the process of the external communication of Chinese martial arts culture, we should pay attention to maintaining the cultural features of national martial arts, standardizing the English expression of martial arts terms, and expanding the external communication channels of martial arts in multiple approaches and all-around ways, so as to promote the cross-cultural communication of wushu and highlight the spirit of Chinese culture.

\section{Acknowledgments}

The author would like to thank the reviewer of the journal for their consideration accepted this article. As well as thank the editor for their valuable time, advice and support. This work was supported by the Research Fund provided by Social Science Planning Project of Henan Province (She Ke Gui Hua, Project Number: 2018BYY009). 


\section{References}

Dong, S.M. (1990). Fine Theories of Chinese Contemporary Qigong. Beijing: People's Sports Publishing Company. Du, Y. F. (2010). Zero translation and translation of martial arts terms. Wushu Science, (1), 25-26.

Guo, Q. (2006). Research on Wushu International Communication Strategy (Dissertation), Guangxi Normal University.

Huang, Z. (2012). Research on the Internationalization Mode of Chinese Martial Arts (Dissertation), Henan University.

Krippendorff, K. (2012). Content analysis: An introduction to its methodology. Thousand Oaks, CA: Sage.

Liu, Y. M. (2006). From "Being Faithful to Source to "Being Responsible to Sourse Culture": Toward a New Norm of Translation. Chinese Translators Journal, (27)6,32-36.

Luo, Y. Z. (2008). The Status Quo and Countermeasures of Chinese Wushu Translation. Foreign Language Learning Theory and Practice, (4), 58-63.

Opinions on Strengthening the Protection of Intangible Cultural Heritage in China. [Online] Available: http://www.gov.cn/zwgk/2005-08/15/content_21681.htm Retrieved on December 30, 2017

Patton, M. Q. (2002). Qualitative research \& evaluation methods, Thousand Oaks Sage Publications. New York, New Delhi, London.

Qiu, M. R. (2001). Translatability and Zero Translation. Chinese Translators Journal, (22)1, 26-28.

Schmidt, H. (2001). Globalization and Moral Reconstruction.

Shi, H. W., Jiang, B. Y. (2008). The Intangible Cultural Heritage of the Central Plains and Its Significance. Journal of North China University of Water Resources and Electric Power (Social Science Edition), (6), 63-66.

The Convention for the Safeguarding of the Intangible Cultural Heritage. (2013) Available at https://baike.baidu.com/ Retrieved on December 30, 2013

Wang, G. \& Wang, T. X. (2005). Cultural Review of the Development of National Traditional Sports. Beijing: Beijing Sport University Press.

Wang, G. (2009). The ultimate goal of Chinese martial arts communication: culture first. Wushu Science, (6), 34.

Xie, Y. X. (2008). Strategies for Translating Wushu Texts. Chinese Translators Journal, (1), 61-64.

Yang, C. C. (2006). Henan: The Central Plains of Chinese Culture. Beijing: Foreign Languages Press.

Zhang, S. (2003). Chen Style Taijiquan Competition Routine. Taiyuan: Shanxi Science and Technology Press.

Liu, X. (2018). International communication of intangible cultural heritage in central plains: a case study of Chinese Wushu. International Journal of Social Sciences and Humanities, 2(3), 196-204. https://doi.org/10.29332/ijssh.v2n3.238 


\section{Biography of Author}

Xia Liu is a lecturer of Faculty of International Studies, Henan Normal University. She
is a lecturer of Culture Translation, Basics of Chinese Culture and Contrastive Studies of
English and Chinese. Her research interests include ELT and translation studies.
Email: nancylx@aliyun.com

